\title{
The Psychological Development Features and Health Maintainance for Middle School Students Xuelian $\mathrm{Lu}^{1, \mathrm{a}}$
}

\author{
${ }^{1}$ School of Educational Science, Tonghua Normal University, Tonghua,Jilin134002,China;
}

aluxuelian1982@sina.com

\begin{abstract}
Keywords: The psychology of middle school students, the psychological development features, persuasion tactics, the psychological health maintainance.
\end{abstract}

\begin{abstract}
The middle school period is called psychological weaning period in psychology. The psychological development of middle school students presents different features from other age stages. Their psychological health standards include the following aspects: learning adaptability, harmonious social relationship, rich feeling of life reality and self-consciousness, nice personality characteristics and personality development. Targeting at their psychological health problems, we mainly adopt persuasion to carry out psychological guidance and healing to maintain their psychological health and to develop their healthy psychology.
\end{abstract}

Fund Project: The partial results in "The education practice study of middle school student's psychological health", Jilin provincial planned research topic. (Project number: GH12409)

\section{The psychological development features of middle school students}

The ages from 13 to 18, which are also called psychological weaning and puberty period, are during the middle school time when school education begins. In middle school, student's psychological development presents distinguishing features. They have more and more experiences with social lives; The rapid change of hormone causes great impacts on their psychology, hoping to get the same treatment for their own businesses and viewpoints as the adults; Their self-images and inner social thoughts are often unstable; The mental and physical rapid changes make them have a strong desire to get more attention from others.

From 14 to 16, the middle school students will get into a fastigium of physical development and will show their second sexuality to which they have different reaction. For girls, they will disguise themselves to avoid other people's attention. They often shrink their bodies or put on large and strange clothes to cover their physical changes. For boys, although they do not care much about this kind of physical changes, they worry that they will have a different physical growth from other peers[1].

The rapid psychological change comes after the quick physical growth and strengthens the feeling of being an adult. They think they have grown up and become adults. They also feel they should be independent and create their own worlds. Too much interference from parents and teachers will cause psychological inversion on them. They hope to get free friendship from their peers and equal treatment as the adults. They can draw up their plans positively and carry out them effectively.

The mental and physical rapid changes will cause the students to reset their self-images, which are not stable. Their outlooks on life and value are developing. To them, the study is not an easy-doing mission and their adaptation to study will influence their psychological health. For various reasons, such as the unsuitable learning and testing methods, they may meet a lot of difficulties on their studies. Too much concerning about their academic achievements generates great fear at the exams. Their general practice is to indulge themselves into the sea of testing papers, which sacrifices their natural activities and interests, making the wonderful puberty a hard period of psychological disorder.

By analyzing the psychological development features of middle school students, we found there 
are both objective reasons and inner inevitability. The main reasons deciding psychological health include: stable self-identity, high-level value system and harmonious personal relationship. Erickson believes that developing self-identity is the main psychological mission in the puberty, which is to determine the future life strategies[2]. Bross holds the opinion that the second psychological born is an inevitable hard mental change during the growing process from childhood to adult. Its main processes include separation and individualization. The negative effects coming from separation process must be compensated by self-identity and new-level individuality. At the same time, the realization of individualization depends on students' keeping pursuing self-independence, courageous exploring and the help from parents and teachers.

\section{Middle school students' psychological health: its main standards and contents}

Middle school students' psychological health standard can be illustrated from the following four aspects: good learning adaptability, harmonious social relationship, rich feeling of life reality and self-consciousness, personality development[3].

\subsection{Good learning adaptability.}

Middle school students' good learning adaptability is to takes them as a relatively independent learning individual, put them in a personalized learning environment, reorganize and construct their infrastructure, combine the original knowledge media, consider the relative teaching activity and realize their personalization of learning and learning activities. Their original knowledge can make up the learning adaptive system, under which assistance they can gain knowledge and improve their abilities. The learning process under this system includes: self organization and reestablishment of original knowledge, formulation and execution of study plan, independent choice of learning strategy, the control and adjustment of learning process and self summary and assessment of learning outcomes. The students with healthy psychology will put up the following features: positive learning attitude, strong learning consciousness, specific and definite learning purpose, flexible learning method, the agreement between study plan and self characteristic, strong learning will, enough learning and testing confidence.

\section{2 Harmonious social interpersonal relationship.}

Social interpersonal relationship refers to a direct, psychological relation established in the activities of social production and practical lives among different people. The middle school student's social interpersonal relationship mainly includes: relative, friend, teacher and student, classmate etc.. It has a strong influence on student's mood, life and work(atmosphere, communication, operation and efficiency in organization). The students with healthy psychology will show few conflicts with others, harmonious relation with relatives, friends, teachers and classmates and easy communication with others. They are sincere, generous, sympathetic and warm hearted.

\subsection{Substantial feeling of life reality and self-consciousness.}

Self-consciousness refers to the ability that one can perceive his own physical change and mental activity. That is to say one can clearly know his own physiological character and status, the features of mental activities, his relation with others and its meanings. The feeling of reality is the understanding of relation between individual and reality. The self-consciousness has a close connection with attitude and behavior choice. The good self-consciousness can help people correctly realize himself and his connection with other things and treat himself and relating matters. From the aspect of the feeling of life reality and self-consciousness, the middle school students represent objective self-consciousness, proper self-acceptance, upward self-practice and effective self-control[4].

\subsection{Good personality characteristics and development.}

Personality is the summation of all psychological features. It has certain tendency and peculiarity. Its tendentiousness and psychological feature make up people's personality structure, which effects people's work efficiency, learning progress and living mood. To some extent, the personality structure also decide people's living habits and behavior pattern. When a middle school student's personality functions well, he will show good personality traits and healthy character and the 
personality govern his life, study and emotion. However, when his personality performs badly, he will have some difficulty controlling his emotions and feel bored and boneless. In terms of personality characteristics and development, the middle school student with healthy personality will show harmonious relation among the needs, motivation, ideals and value. One's quality, character and ability will have a good social adaptiveness and provide guarantee and support to middle school student's life, study, emotion and healthy personality.

\section{Health maintenance of middle school students' psychology: applying persuasion strategy}

The persuasion strategy refers that schools help their students recover from their mental diseases by using verbal and subvocal language to help students communicate, which can cure and maintain students' psychological problems. The persuasion strategy can de divided into collective and individual persuasion. The collective one is to counsel for the whole class or group, point out the problems and the solutions. The individual one only targets at one student and offers the specific solving strategies. No mater which way can be taken, during this process, there are three phases: diagnosis, curing and consolidation. The main points in persuasion strategy include:

\subsection{Guiding the middle school students to make information feedback.}

The purpose of this is to get the instant result of information. During the persuasion strategy, feedback circuit can control the student's psychological status and balance. With the circuit, student can discover and realize himself, which can arouse student's inner motives and interests[5].

\subsection{Cultivating students to be more confident.}

Having self-confidence is the key to the success of persuasion strategy. Being self confident, the student will change their attitude and take part in the psychological guidance positively, which is helpful to maintain the students' healthy psychology.

\subsection{Motive the student to comprehend new thinking.}

The comprehension of new thinking is to combine various psychological factors(memory, association, reasoned thinking and autoscopia), which can improve student's psychological activity, solve their puzzled problems and enhance their psychological impetus.

\subsection{Develop students' ability of self-knowledge and control.}

Self-knowledge and control is the basic requirement for them to develop whole self-consciousness,, and its establishment needs different factors(recognize and control yourself, make objective judgment on others). The right and positive strategy of self-knowledge and control is to pay close attention to yourself, accumulate advantages, highlight the shining point and constitute healthy wonderful life.

\section{References}

[1]. Xiangrong Liu.The Relationship among Learning Anxiety, Scholastic Attainment and Psychological Health of Middle School Students.[J]Modern Education of Primary and Secondary School Students, 2014,(3)

[2]. Hua Xie.The Analysis of Middle School Student's Psychological Health Status, Problem and Solution[J]Teaching and Management,2014(6)

[3]. Bihua Cao.Qualitative Research of Psychological Health Standard-Based on Psychology Teacher and Student in Middle School[J]College of Liao Ning Educational Administration,2014,(4)

[4]. Jianying Rong.The Statistic Analysis of Middle School Student's Psychological Health Status[J]Psychology on Campus,2014,(4)

[5]. Robert.<Personality and Behavior: The Base Managerial Psychology $>[\mathrm{M}]$. Beijing Machine Press,2011 